\title{
Progress on the Development of a Superconducting Connection for Niobium Cavities
}

\author{
Peter Kneisel, Gianluigi Ciovati, Jacek Sekutowicz, and Larry Turlington
}

\begin{abstract}
The availability of a superconducting connection between adjacent niobium radio-frequency (RF) cavities with the capability to carry up to $30 \mathrm{mT}$ of the magnetic flux would be particularly of great benefit to layouts of long accelerators like the International Linear Collider (ILC). It would shorten the distances between structures and therefore the total length of an accelerator with the associated cost reductions. In addition, the superconducting connection would be ideal for a superstructure two multi-cell cavities connected through a half wavelength long beam pipe providing the coupling. Two single-cell niobium cavities have been designed with $\mathrm{Nb}-1 \mathrm{Zr}$ flanges welded to one of the irises to allow a connection between them with a niobium gasket. A transition to the normal-conducting state of the connection due to the applied RF field causes a reduction of the cavities' quality factor. The cavity design will be presented in this contribution along with possible choices of materials for the joint.
\end{abstract}

Index Terms-Niobium, Niobium alloys, Superconducting accelerator cavities, Superconducting devices.

\section{INTRODUCTION}

A superconducting connection between adjacent cavities in a cavity string has been desired for a long time and several attempts have been made in the past to develop such a system [1], [2], [3], [4]. The reasons are as obvious as the technological difficulties: a reliable superconducting connection would allow a shortening of the distances between adjacent cavities - presently connections are being made at locations, where the cavity fields decay to a level which generates only minute losses - providing a more compact design with the associated cost reductions. In addition, it would be possible to manufacture the accelerating cavities typically consisting of a rotationally symmetric center portion (the cells) and asymmetric end groups - more cost effective by e.g. applying "seamless" fabrication technologies [5] for the rotational symmetric center portion. The proposed International Linear Collider (ILC) accelerator, about $38 \mathrm{~km}$

Manuscript received 19 August 2008. This manuscript has been authored by Jefferson Science Associates, LLC under U.S. DOE Contract No. DEAC05-06OR23177. The U.S. Government retains a non-exclusive, paid-up, irrevocable, world-wide license to publish or reproduce this manuscript for U.S. Government purposes.

P. Kneisel, G. Ciovati and L. Turlington are with the Thomas Jefferson National Accelerator Facility, Newport News, VA 23606 USA (phone: 757269-7646; fax: 757-269-7658; e-mail: kneisel@jlab.org).

J. Sekutowicz is with the Deutsches Elektronen-Synchrotron, 22603 Hamburg Germany (e-mail: jacek.sekutowicz@desy.de). long in the actual design [6], would greatly benefit from the availability of a superconducting connection joining two 9-cell cavities in a superstructure configuration [7]. The design accelerating gradient for ILC is $31.5 \mathrm{MV} / \mathrm{m}$, corresponding to about $133 \mathrm{mT}$ peak surface magnetic field $\left(\mathrm{B}_{\mathrm{p}}\right)$ in the cavities. The ratio between $B_{p}$ in the cavities and the magnetic field at the joint location is about six in the superstructure configuration; therefore the joint would have to sustain about $22 \mathrm{mT}$ at $2 \mathrm{~K}$ without losses. In addition, the development of superconducting cavities has gone in the direction of immersing only the "cell section" of a cavity in liquid helium, whereas the end groups (fundamental power coupler, higher order mode couplers) are cooled by conduction only. A superconducting joint would therefore be placed outside the helium bath and a high thermal conductivity of the joint materials is essential. Fig. 1 shows the superstructure configuration with the approximate location of the superconducting joint.

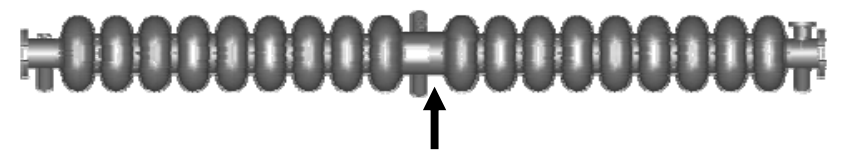

Superconducting Joint

Fig. 1. Two 9-cell cavities in the superstructure configuration.

\section{Possible Joint Materials}

Besides being superconducting up to a field of about $22 \mathrm{mT}$ at $2 \mathrm{~K}$, the joint has to be ultra-high vacuum (UHV) tight. To accomplish this we adopted the Conflat design, where a knifeedge is machined on the flanges and a soft superconducting disk is used as a gasket. Indium based joints, which had been used in the past, are not suitable since its critical field at $2 \mathrm{~K}$ is about $15 \mathrm{mT}$ [8]. We considered using high purity niobium as gasket material, due to its excellent radio-frequency superconducting (SRF) properties and because it is a relatively soft metal. Flanges made of $\mathrm{Ti}-45 \mathrm{Nb}$ are much harder than niobium and are presently used on 9-cell cavities but both the very low thermal conductivity $\left(\sim 0.03 \mathrm{~W} \mathrm{~m}^{-1} \mathrm{~K}^{-1}[9]\right)$ and lower critical field $(\sim 10 \mathrm{mT}[10])$ than niobium at $2 \mathrm{~K}$ does not make it a good candidate material for this application. Nb$1 \mathrm{Zr}$ alloy is a material harder than niobium and had been considered for the fabrication of flanges for SRF niobium cavities. A single-cell cavity, one half cell made of Nb-1Zr the other half made of high purity $\mathrm{Nb}$, achieved $\mathrm{B}_{\mathrm{p}}=42 \mathrm{mT}$ at 2 $\mathrm{K}$, making this material a good candidate for the cavity 
flanges. An even more desirable material would be $\mathrm{NbN}$ in form of a thin, but mechanically very strong layer on top of a solid niobium flange, which would provide a much better thermally stabilized system than Nb-1Zr. However, this material is not readily available and further research is needed to develop it. The RF test of a NbN single-cell cavity at $2 \mathrm{~K}$, where the $\mathrm{NbN}$ layer was grown by exposing a niobium cavity to nitrogen gas at $\sim 1200{ }^{\circ} \mathrm{C}$ in an UHV furnace, showed a quench at $\mathrm{B}_{\mathrm{p}}=55 \mathrm{mT}$. The quality factors $\left(\mathrm{Q}_{0}\right)$ measured as a function of $B_{p}$ at $2 \mathrm{~K}$ for cavities made of Ti- $45 \mathrm{Nb}$, Nb/Nb$1 \mathrm{Zr}$ and $\mathrm{NbN}$ are shown in Fig. 2. The surface treatment in all cases was buffered chemical polishing (BCP). More details can be found in [11].

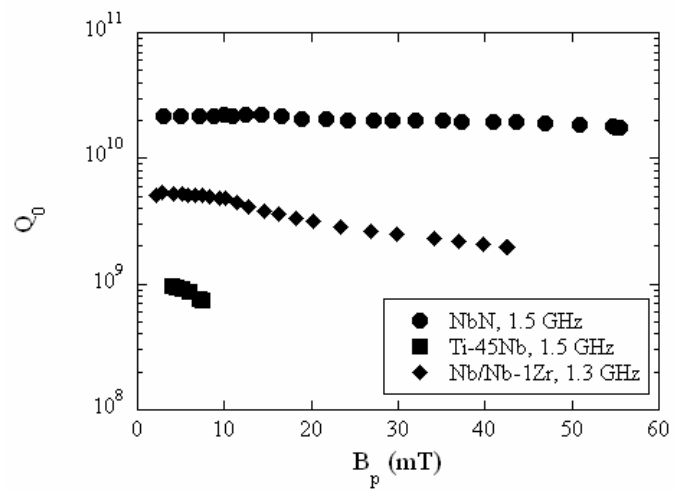

Fig. 2. $\mathrm{Q}_{0}\left(\mathrm{~B}_{\mathrm{p}}\right)$ at $2 \mathrm{~K}$ for single-cell cavities made of different materials. The limitation in all cases was a quench.

\section{2-CELL JoINT CAVITY DESIGN AND FABRICATION}

In order to test the SRF properties of the joint, we designed and built a cavity made of two single-cells with an enlarged iris in the middle which could accommodate a $115 \mathrm{~mm}$ inner diameter Conflat-style flange. The electromagnetic properties of the $\mathrm{TM}_{010^{-}} 0$ and $-\pi$ modes for this cavity have been computed with a 2D finite element code [12] and the main parameters are indicated in Table I. The magnetic field at the joint location $\left(\mathrm{B}_{\mathrm{J}}\right)$ is approximately a factor 2.5 lower than at the equator of the cells in the 0 -mode, while it is zero in the $\pi$ mode. Fig. 3 shows the calculated surface magnetic field distribution along the cavity contour for both modes.

TABLE I Electromagnetic Parameters of the TM $\mathrm{M}_{010}$ Modes of the 2-CELl JOINT CAVITY CALCULATED FOR A STORED ENERGY OF $1 \mathrm{~J}$

\begin{tabular}{ccc}
\hline \hline Parameters & $\mathrm{TM}_{010}-0$ & $\mathrm{TM}_{010}-\pi$ \\
\hline Frequency $(\mathrm{MHz})$ & 1314.0 & 1334.3 \\
Geometry factor $(\Omega)$ & 294.7 & 295.1 \\
$\mathrm{~B}_{\mathrm{p}}(\mathrm{mT})$ & 24.0 & 25.2 \\
$\mathrm{~B}_{\mathrm{J}}(\mathrm{mT})$ & 9.45 & 0 \\
$\mathrm{E}_{\mathrm{p}}(\mathrm{MV} / \mathrm{m})$ & 10.6 & 10.8 \\
$\mathrm{E}_{\mathrm{J}}(\mathrm{MV} / \mathrm{m})$ & 0 & 3.75 \\
\hline \hline
\end{tabular}

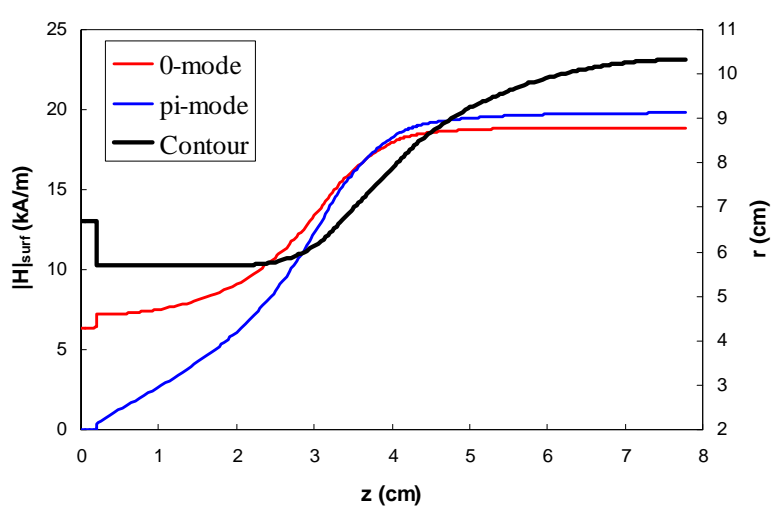

Fig. 3. Surface magnetic field along the cavity contour (black line), calculated for both $\mathrm{TM}_{010^{-}} 0$ (red line) and $-\pi$ (blue line) modes of the 2-cell joint cavity for a total stored energy of $1 \mathrm{~J}$.

The cells were fabricated from large-grain niobium supplied by CBMM with residual resistivity ratio (RRR) $\geq 280$. Due to its ready availability, we decided to fabricate the Conflat-style flanges from $\mathrm{Nb}-1 \mathrm{Zr}$, machined from material supplied by W. C. Heraeus. Standard fabrication methods such as deep drawing of the half-cells and electron beam welding for joining the various parts were used. All cavity parts machining and the welding were done at Jefferson Lab; all welds, even those at the equator, were "inside-outside" welds. Two niobium plates were welded on the beam tube and near the joint for each cell and will be part of an integrated helium vessel which will allow isolating the joint from the He bath. A ring (140 mm outer diameter, $127 \mathrm{~mm}$ inner diameter) $2 \mathrm{~mm}$ thick made of high RRR niobium, cut from a niobium sheet, is used as gasket between the $\mathrm{Nb}-1 \mathrm{Zr}$ flanges. Fig. 3 shows a picture of the assembled 2-cell joint cavity.

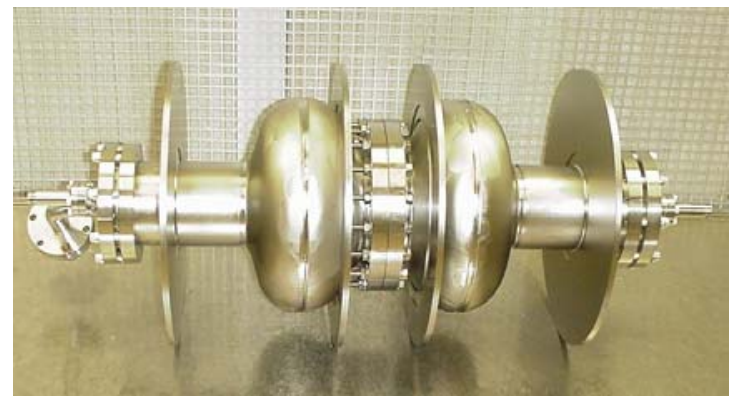

Fig. 3. Completed 2-cell joint cavity.

The joint was UHV-tight after the first assembly and cryogenic cycling to $2 \mathrm{~K}$. Nevertheless, after disassembling the joint at room temperature, we noticed that the knife-edge had significantly "flattened" due to the compression with the $\mathrm{Nb}$ gasket. Measurements of the Vickers hardness of the various materials will be discussed in the next section.

\section{MEASurements on SAmples}

We measured the Vickers hardness of various possible materials for the flange/gasket superconducting joint, in particular:

(1) fine-grain (ASTM 6), high purity Nb sample, 
chemically etched by BCP

(2) same as (1) followed by post-purification with $\mathrm{Ti}$ in a UHV furnace at $\sim 1100{ }^{\circ} \mathrm{C}$ for $\sim 66 \mathrm{~h}$, followed by BCP

(3) Ti-45Nb sample, treated with BCP

(4) Nb-1Zr sample, treated with BCP

(5) NbN sample, obtained by exposing niobium at $\sim 1200$ ${ }^{\circ} \mathrm{C}$ to a nitrogen atmosphere for several hours.

The results from the measurements are indicated in Table II. These values are consistent with those reported, for example, in [13], except for the $\mathrm{Nb}-1 \mathrm{Zr}$ being about $20 \%$ lower. We suspected the possibility of a zircon concentration lower than the nominal 1 wt.\% value as the cause for the reduced mechanical strength. Indeed, analysis by energy dispersive $\mathrm{X}$ ray (EDX) over an area of $1 \mathrm{~mm}^{2}$ showed a zircon concentration of $0.38 \mathrm{wt} . \%$ at the surface (1-2 $\mu \mathrm{m}$ deep) and of 0.84 wt.\% a few hundred micrometers below the surface.

TABLE II VICKERS HARDNESS MEASURED ON SAMPLES OF DIFFERENT MATERIALS FOR THE SUPERCONDUCTING JOINT

\begin{tabular}{cc}
\hline \hline Material & Vickers Hardness \\
\hline Fine-grain Nb & 51 \\
Post-purified Nb & 38 \\
Ti-45Nb & 178 \\
Nb-1Zr & 97 \\
NbN & 150 \\
\hline \hline
\end{tabular}

The availability of a setup to measure the critical field of a joint made with the same flange and gasket materials at $2 \mathrm{~K}$ would complement the RF measurements in the 2-cell cavity and would help identifying a set of preparation procedures to obtain $\mathrm{B}_{\mathrm{J}} \geq 25 \mathrm{mT}$. One possibility is to measure the self-field critical current across the joint. We prepared $38 \mathrm{~mm}$ long samples, $3 \mathrm{~mm} \times 6 \mathrm{~mm}$ cross-section, with two knife-edges machined on the $3 \mathrm{~mm}$ long side, from Nb-1Zr and Ti-45Nb. We also prepared $38 \mathrm{~mm}$ long $\mathrm{Nb}$ samples, $3 \mathrm{~mm} \times 3 \mathrm{~mm}$ cross-section, which are pressed against the knife-edges to make the joint. Standard 4-wire technique is used to measure the voltage across the joint as a function of the applied DC current. Initial tests at $2 \mathrm{~K}$ showed low values of the self-field critical current due to field enhancement at the edges of the samples. This was reduced by rounding the corners of the samples with chamfers, $1 \mathrm{~mm}$ radius. An additional problem is that the cross-section of the samples should be reduced to $\sim 1$ $\mathrm{mm} \times 1 \mathrm{~mm}$ in order to limit the current necessary to produce a surface magnetic field of $25 \mathrm{mT}$ to about $100 \mathrm{~A}$, making the joint preparation more challenging.

\section{CONCLUSION}

The availability of a superconducting connection between cavities capable of sustaining a magnetic field of about $25 \mathrm{mT}$ without losses could have a significant impact on the cost of accelerators such as the proposed ILC. To guarantee a UHV- tight connection, we adopted the Conflat design and we are in the process of evaluating suitable superconducting materials for the flange/gasket assembly. RF measurements on singlecell cavities indicated $\mathrm{Nb}-1 \mathrm{Zr}$ and $\mathrm{NbN}$ as good candidates for the flanges, being also harder than niobium, which is the chosen gasket material. We designed and built a 2-cell cavity with the joint between the two cells, which will be used to test the SRF properties of the joint at $2 \mathrm{~K}$. A setback was due to the discovery that the $\mathrm{Nb}-1 \mathrm{Zr}$ material provided by the vendor had lower zircon concentration than the nominal amount, causing the material to be "softer" than required in order to maintain a sharp knife-edge after pressing on the gasket. We are preparing a setup to measure the self-field critical current of small size joint samples to complement the $\mathrm{RF}$ measurements of the 2-cell cavity. In addition, we are following the promising route of developing processing parameters for $\mathrm{NbN}$ layers on niobium by either thermal nitrification or plasma nitrification, with emphasis on obtaining good superconducting properties.

\section{ACKNOWLEDGMENT}

We would like to thank G. Slack, R. Bundy and B. Clemens for helping with the cavity fabrication, A. Wu for the EDX measurements and G. Myneni for the hardness measurements.

\section{REFERENCES}

[1] M. Grundner, H. Lengeler, and E. Rathgeber, "RF contact for superconducting resonators”, Nucl. Instr. and Meth., vol. 141, pp. 57-59, Feb. 1977.

[2] M. S. McAshan, H. A. Schwettmann, L. Suelzle, and J. P. Turneaure, "Development of the superconducting accelerator", HEPL Report 665, 1972, unpublished.

[3] H. Heinrichs and W. Weingarten, "An RF contact for superconducting cavities”, Nucl. Instr. and Meth., vol. 171, no. 1, pp. 185-88, Apr. 1980.

[4] K. W. Shepard and M. Olesen, "ATLAS design notes: superconducting RF demountable joint”, 2005, unpublished.

[5] W. Singer, "Seamless/bonded niobium cavities", Physica C, vol. 441, no. 1-2, pp. 89-94, July 2006.

[6] N. Phinney, N. Toge, and N. Walker. (August 2007). International Linear Collider Reference Design Report. Volume 3: Accelerator. Available: http://www.linearcollider.org/cms/?pid=1000437.

[7] J. Sekutowicz, M. Ferrario, and Ch. Tang, "Superconducting superstructure for the TESLA collider: A concept”, Phys. Rev. ST Accel. Beams, vol. 2, no. 6, 062001, June 1999.

[8] Y. Bruynseraede, D. Gorle, D. Leroy, and P. Morignot, "Surfaceresistance measurements in the $\mathrm{TE}_{011}$-mode cavities of superconducting indium, lead and an indium-lead allow at low and high RF magnetic fields”, Physica, vol. 54, no. 1, pp. 137-59, Aug. 1971.

[9] E. W. Collings, Applied Superconductivity, Metallurgy, and Physics of Titanium Alloys, New York: Plenum Press, 1986, Vol. 1, p. 267.

[10] S. Giordano, H. Hahn, H. J. Halama, T. S. Luhman, and W. Bauer, "Investigation of microwave properties of superconducting $\mathrm{Nb}_{0.4} \mathrm{Ti}_{0.6}$ ", IEEE Trans. Magn., vol. 11, no. 2, pp. 437-40, March 1975.

[11] P. Kneisel, G. Ciovati, J. Sekutowicz, A. Matheisen, X. Singer and W. Singer, "Development of a superconducting connection for niobium cavities", in Proc. 2007 Part. Accel. Conf., Albuquerque, 2007, pp. 2484-86.

[12] J. Sekutowicz, "2D FEM code with third order approximation for RF cavity computation”, in Proc. 1994 Linear Acc. Conf., Tsukuba, 1994, pp. 284-86.

[13] H. Kaiser, X. Singer, and W. Singer, "Materials for the flanges of TESLA cavity”, TESLA Report 99-04, 1999, unpublished. 